Abstract

\title{
A Reconstruction of Organization Management Model on the Basis of Complex Information System Theory and Technological Innovation ${ }^{+}$
}

\author{
Yan Yuan \\ School of Humanities and Social Sciences, Xi' an Jiaotong University, Xianning West Road, Xi'an City 710049, \\ Shaanxi Province, China; yuanyu1007@126.com \\ † Presented at the IS4SI 2017 Summit DIGITALISATION FOR A SUSTAINABLE SOCIETY, Gothenburg, \\ Sweden, 12-16 June 2017.
}

Published: 9 June 2017

\begin{abstract}
The series of concepts that are presented by complex information system theory, like the ontological information, information system and so on, not only can exploit new approach for the development of system thoughts, but also can provide the innovation of organization management theories a new horizon or route. As the core constituents of organizations, modern organization management models should be adjusted continuously according to the progress of our time, in order to conform to the development of organizations. And in a time dominated by information technology and information economy, the complex-information-relationships-based technological innovation will help to upgrade modern organization management models, which means that, based on such technological innovation, a brand-new organization management model conforming to characteristics of complex information system can be constructed. This article tries to reconstruct the organization management model by using the complex information system theory and by analyzing the relevant technological innovation. And this reconstructed organization management model, on one hand, can highlight the effectiveness of "information" in the organization management, to tally with the theme of our time; on the other hand, it gives the organization management model a holistic dynamic generation characteristic, to maintain the vitality of the model and to adapt the development nature of organizations
\end{abstract}

Keywords: technological innovation; organization management; complex information system

(C) 2017 by the authors. Licensee MDPI, Basel, Switzerland. This article is an open access article distributed under the terms and conditions of the Creative Commons Attribution (CC BY) license (http://creativecommons.org/licenses/by/4.0/). 